\title{
Identification of peripheral inflammatory markers between normal control and Alzheimer's disease
}

\author{
Sam-Moon Kim², Juhee Song ${ }^{1}$, Seungwoo Kim', Changsu Han², Moon Ho Park ${ }^{3}$, Youngho Koh', \\ Sangmee Ahn Jo ${ }^{1}$ and Young-Youl Kim ${ }^{1 *}$
}

\begin{abstract}
Background: Multiple pathogenic factors may contribute to the pathophysiology of Alzheimer's disease (AD). Peripheral blood markers have been used to assess biochemical changes associated with AD and mild cognitive impairment $(\mathrm{MCl})$ and involved in their pathophysiology.

Methods: Plasma samples and clinical data were obtained from participants in the Ansan Geriatric Study (AGE study). Plasma concentrations of four candidate biomarkers were measured in the normal control ( $\mathrm{NC}), \mathrm{MCl}$, and AD group: interleukin-8 (IL-8), IL-10, monocyte chemoattractant protein-1 (MCP-1), and tumor necrosis factor- $\alpha$ (TNF- $\alpha$ ).

Body mass index (BMI), MMSE (Mini Mental State Examination), CDR(Clinical Dementia Rating) score and homocystein level were recorded with social and demographic information.

Results: Total of 59 subjects were randomly selected for this analysis [NC $(n=21), M C I(n=20)$ and $A D(n=18)]$. In demographic data, educational year was correlated with the diagnosis states $(\boldsymbol{p}<0.0001)$. No significant differences in cardiovascular disease, BMI and use of NSAIDs were found in MCI or AD group compared with NC group, respectively. The involvement of inflammatory illness or conditions in subjects, WBC count, fibrinogen and homocystein of the three groups, but no significant differences were found in each groups. The plasma IL-8 level was lower in $\mathrm{MCl}$ and $\mathrm{AD}$ patients compared with the normal control group (respectively, $p<0.0001$ ). The $\mathrm{MCl}$ and AD patients had similar MCP-1, IL-10, and TNF- $\alpha$ level.
\end{abstract}

Conclusions: Our study suggests the existence of an independent and negative relationship between plasma IL-8 levels and functional status in $\mathrm{MCl}$ and $\mathrm{AD}$ patients.

Keywords: IL-8, biomarker, Alzheimer's

\section{Background}

Over the past decade, it has become clear that the brain maintains intricate relationships with the immune system. For example, proteins secreted from the brain can regulate physiological processes throughout the body [1]. In Alzheimer's disease (AD), the characteristic amyloid plaques and tangles in the brain are accompanied by prominent local stimulation of innate immune and inflammatory responses [2]. The possibility that inflammatory cytokines play a role in inflammation in the $\mathrm{AD}$

\footnotetext{
* Correspondence: youngyk@gmail.com

${ }^{1}$ Center for Biomedical Science, Division of Brain Diseases, National Institute of Health in Korea (KNIH), Osong Health Technology Administration Complex 643 Yeonje-ri, Gangoe-myeon, Chungcheongbuk-do, 363-951, Republic of Korea

Full list of author information is available at the end of the article
}

brain was initially suggested by the observation that the concentrations of these molecules are increased in $\mathrm{AD}$ tissue and are prominently associated with AD lesions $[3,4]$. The inflammatory cytokines are products of activated microglia and astrocytes, and they stimulate the phagocytotic activity of microglia. The localization of cytokines to activated glial cells has been demonstrated in AD brain tissue by immunohistochemistry $[5,6]$.

Nevertheless, clinical studies of the potential role of inflammation in AD have yielded inconsistent results. Whereas several community-based studies have linked anti-inflammatory interventions to a lowered risk of developing $\mathrm{AD}$ [7], a randomized, placebo-controlled clinical trial failed to demonstrate a beneficial effect of

\section{() Biomed Central}

(c) 2011 Kim et al; licensee BioMed Central Ltd. This is an Open Access article distributed under the terms of the Creative Commons Attribution License (http://creativecommons.org/licenses/by/2.0), which permits unrestricted use, distribution, and reproduction in any medium, provided the original work is properly cited. 
nonsteroidal anti-inflammatory drugs (NSAIDs) on the progression of $\mathrm{AD}[8]$.

Other observational studies that have evaluated the relationships between markers of systemic inflammation and $\mathrm{AD}$ risk have been inconclusive: circulating cytokines have been reported to be elevated [9], decreased [10], or unaltered [11] in AD patients compared with cognitively intact controls. The observed differences might partly be explained by differences in the study populations, such as inclusion criteria or the number of subjects. Nevertheless, the identification of an inflammatory biomarker of $A D$ is required to improve the accuracy of diagnosis and monitor disease progression. In addition, it might be useful diagnostically as an early AD biomarker in combination with other biological markers [12].

Recent evidence suggests that the pathological process in AD begins many decades before the appearance of overt symptoms [13] and that AD rates are predicted to rise substantially in the coming decades [14]. Consequently, non-invasive, readily accessible peripheral biomarkers with a high degree of sensitivity and specificity would be ideal for screening at-risk individuals. In this study, we examined whether cytokines could be potent biomarkers for diagnosing AD. We measured the levels of four candidate biomarkers (IL-8, IL-10, MCP-1 and TNF- $\alpha$ ) in plasma samples and compared them with the risk of developing $\mathrm{AD}$ in Asian subjects.

\section{Methods}

\section{Study population}

Plasma cytokine levels and clinical data were obtained from participants in the Ansan Geriatric Study (AGE study) $[15,16]$. A total of 1,391 subjects (595 men and 796 women) were randomly recruited between September 2004 and March 2006. The follow-up assessment occurred from 2006 to 2008 (second-wave study; 25.61 \pm 5.08 months), with uniform, structured follow-up evaluations performed by examiners who were blinded to the collected data. In all, 841 subjects were recruited randomly from the first-wave study. The second followup sample $(\mathrm{n}=600)$ was recruited between 2008 and 2009. Among the second follow-up group, total of 59 subjects were randomly selected for this analysis. Informed written consent for participation was obtained from each individual, and the study protocol was approved by the institutional review board of the AGE study. All subjects with recent infections or myocardial infarction or who had undergone antiplatelet, antihypertensive, antineoplastic, or immunosuppressive drug treatments were excluded from the study.

\section{Diagnosis of dementia}

Dementia was defined according to the diagnostic features of dementia given in the Diagnostic and Statistical
Manual of Mental Disorders, fourth edition (DSM-IV) [17]. The sub-diagnosis of possible or probable Alzheimer's disease was based on the National Institute of Neurological and Communicative Disease and StrokeAlzheimer's Disease and Related Disorder Association (NINCDS-ADRDA) criteria [18]. The diagnosis of mild cognitive impairment (MCI) was made in accordance with the clinical criteria of Peterson et al. [19].

\section{Measurements of plasma cytokine concentration}

Blood samples were taken from participants after an overnight fast. Plasma was separated from the blood samples, and the cytokine concentrations were measured. We measured IL-8, IL-10, MCP-1, and TNF- $\alpha$ using the BioPlex cytokine assay (Human Group I assay panel, Bio-Rad, Veenendaal, The Netherlands). In addition, we quantified the plasma IL-8, IL-10, MCP-1, and TNF- $\alpha$ levels using enzyme-linked immunosorbent assays (ELISAs) to confirm the BioPlex data. ELISAs were carried out with the Human ELISA kit (R\&D Systems, Minneapolis, MN, USA) according to the manufacturer's instructions.

\section{COX-2 determination by western blot}

Platelet proteins were separated in 10\% SDS-PAGE and electroblotted to PVDF membranes in a buffer containing $0.025 \mathrm{M}$ Tris- $\mathrm{HCl}, 0.192 \mathrm{M}$ glycine, $\mathrm{pH}$ 8.3, at $230 \mathrm{~mA}$ for $2 \mathrm{~h}$ and $30 \mathrm{~min}$. After blocking with 10\% non-fat milk, immunostaining reaction was performed with a polyclonal antibody raised against $\mathrm{N}$-terminal of COX-2 (N-20; Santa Cruz Biotechnology). A peroxidase conjugate secondary antibody was used (Santa Cruz Biotechnology). The concentration of the protein was determined by Bio-Rad Protein Assay (Bio-Rad). Equivalent amounts of protein $(100 \mu \mathrm{g})$ were fractionated on $10 \%$ SDS polyacrylamide gel overnight, and proteins were transferred to nitrocellulose membranes under semidry conditions. After incubation, the band intensities were evaluated by bioimaging system (MultiGenius, Syngene, USA) and bands were quantified on digitized images.

\section{Statistical analyses}

Cytokines levels were reported as the mean \pm standard deviation (SD). Independent chi-square test and oneway analysis of variance (ANOVA) were used to compare diagnosis states. The results were reported separately for each group (AD patients and control subjects). Statistical analysis was performed using SAS ver. 9.1 (SAS Institute, Cary, NC, USA).

\section{Results}

Table 1 summarizes the demographic factors and clinical characteristics of individual in the normal control $(\mathrm{NC}), \mathrm{MCI}$, and $\mathrm{AD}$ group. The three groups were similar with respect to age and gender. Educational year was 
Table 1 Comparison of the demographic characteristics and dementia-related scale scores of the participants

\begin{tabular}{|c|c|c|c|c|c|}
\hline & NC $(n=21)$ & $\mathrm{MCl}(\mathrm{n}=20)$ & $A D(n=18)$ & $p$-value & ${ }^{*}$ Tukey HSD \\
\hline Age & $75.5 \pm 1.3$ & $76.1 \pm 2.8$ & $75.9 \pm 6.0$ & 0.884 & \\
\hline Gender & & & & 0.954 & \\
\hline Male (\%) & $10(47.6)$ & $9(45.0)$ & $9(50.0)$ & & \\
\hline Female (\%) & $11(52.4)$ & $11(55.0)$ & $9(50.0)$ & & \\
\hline Educational level (y) & $11.6 \pm 3.8$ & $6.6 \pm 4.9$ & $4.7 \pm 4.1$ & $<0.0001$ & $a>b=c$ \\
\hline BMI (\%) & $24.7 \pm .2 .0$ & $24.9 \pm 3.0$ & $22.7 \pm 2.3$ & 0.016 & $a=b>c$ \\
\hline CVD (\%) & 38.1 & 70.0 & 33.3 & 0.044 & \\
\hline NSAIDs use (\%) & 19.1 & 5.0 & 11.1 & 0.423 & \\
\hline MMSE & $27.9 \pm 1.6$ & $24.3 \pm 2.6$ & $15.9 \pm 6.1$ & $<0.0001$ & $a>b>c$ \\
\hline CDR score & 0 & $0.1 \pm 0.2$ & $1.1 \pm 0.8$ & $<0.0001$ & $a<b=c$ \\
\hline GDS score & $6.4 \pm 3.5$ & $7.2 \pm 4.3$ & $8.1 \pm 6.7$ & 0.547 & $a=b=c$ \\
\hline WBC (1000/ul) & $5.7 \pm 1.3$ & $6.4 \pm 1.3$ & $6.9 \pm 1.4$ & 0.046 & $a=b<c$ \\
\hline Fibrinogen (mg/dL) & $318.8 \pm 52.4$ & $351.8 \pm 67.8$ & $356.3 \pm 107.7$ & 0.252 & $\mathrm{a}=\mathrm{b}=\mathrm{c}$ \\
\hline Homocystein (umol) & $15.9 \pm 5.5$ & $17.7 \pm 4.8$ & $19.4 \pm 10.7$ & 0.339 & $a=b=c$ \\
\hline
\end{tabular}

Data are expressed as means \pm standard deviation unless otherwise indicated.

Independent $\chi^{2}$ test and one-way analysis of variance (ANOVA) were used to compare differences between diagnosis states. *Tukey's Studentized Range (HSD) Test.

NC: Normal control.

MCl: Mild cognitive impairment.

AD: Alzheimer disease.

BMI: Body mass index

CVD: Cardiovascular diseases.

NSAIDs: Non-steroidal anti-inflammatory drugs.

MMSE: Mini Mental State Examination.

CDR: Clinical Dementia Rating.

WBC: White Blood Cell.

correlated with the diagnosis states $(\boldsymbol{p}<0.0001)$. However, no significant differences in cardiovascular disease, BMI and use of NSAIDs were found in MCI or AD group compared with $\mathrm{NC}$ group, respectively. We also compared the involvement of inflammatory illness or conditions in subjects, WBC count, fibrinogen and homocystein of the three groups, but no significant differences were found. IL-8 concentrations are related to MMSE, disease stage or progression, negatively. The plasma IL-8 levels in the three study groups are given in Figure 1 . The circulating plasma IL-8 levels were higher in controls than in MCI and AD patients (respectively, $p<0.0001)$. The TNF- $\alpha$ levels were higher in controls compared to AD patients $(p=0.005)$. The plasma TNF$\alpha$ levels were higher in the control group than in the MCI patients, but the difference was not significant (Figure 2). The plasma IL-10 and MCP-1 levels did not differ among the groups (Figure 3).

Inflammatory process is induced cyclooxygenase- 2 (COX-2). The expression of COX-2 is observed a representative western blot in each group (Figure 4). The expression of COX-2 was not changed in patients with $\mathrm{MCI}$ and patients with $\mathrm{AD}$ versus control group.

\section{Discussion}

This study evaluated peripheral markers of inflammation in elderly patients with $\mathrm{MCI}$ or $\mathrm{AD}$ and in normal elderly subjects to assess biochemical changes associated with $\mathrm{AD}$ and $\mathrm{MCI}$ and involved in their pathophysiology.

Interleukin-8, a chemokine produced by macrophage response to proinflammatory mediators such as amyloid, could be important for recruiting activated microglia into sites of the brain damaged by AD [20]. CXCR2, IL-8 receptor, has been localized to dystrophic neurites,

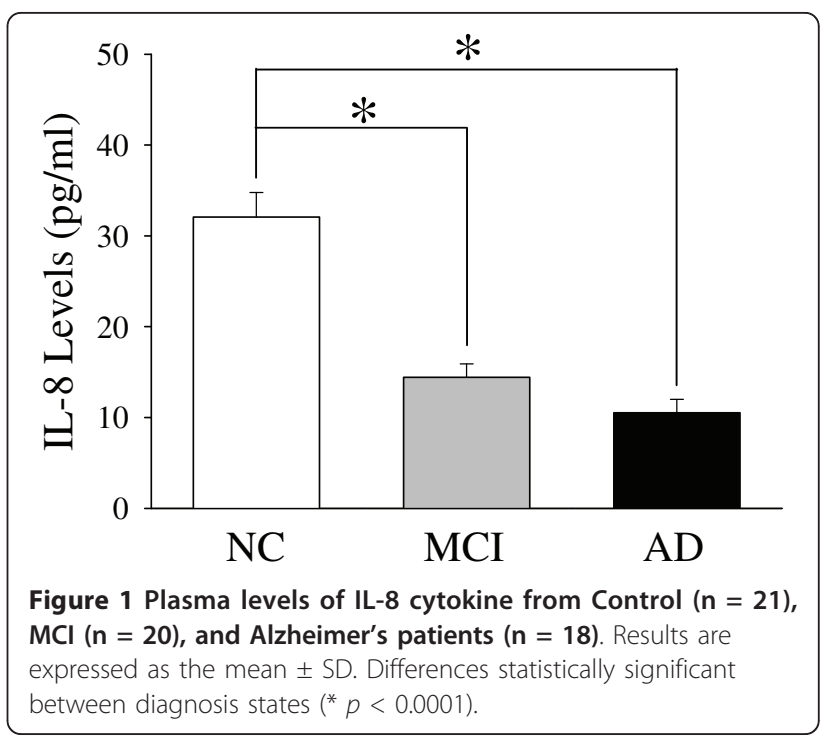




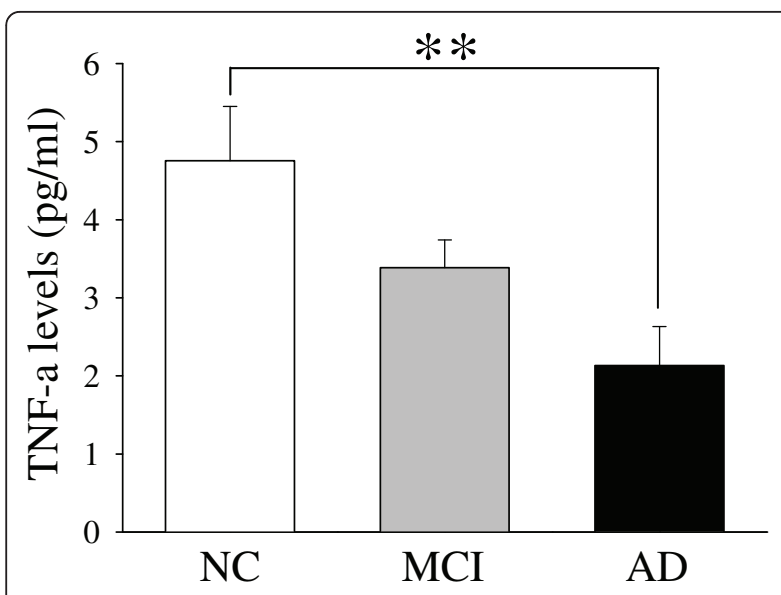

Figure 2 Plasma levels of TNF- $\alpha$ cytokine from Control, $\mathrm{MCl}$, and Alzheimer's patients. Results are expressed as the mean \pm SD Differences statistically significant between diagnosis states ${ }^{* *} p=$ 0.005).

suggesting that IL-8 mediates glial interactions with neurons and thereby contributes to neuronal damage [21]. IL-8 was significantly increased in the cerebrospinal fluid (CSF) in AD compared to controls [22], whereas the plasma IL-8 level in late-onset AD and vascular dementia did not differ from controls in the European subjects [23]. By contrast, our data showed that the IL-8 concentration was significantly lower in patients with MCI or AD compared with the controls. In addition, the ethnic difference of cytokine levels in plasma may exist between Asian subjects and European subjects [24]. However, the levels of COX-2 in the three studied groups have been detected, which could not indicate that it is an enzyme which might be induced with cytokine level. Nevertheless, its diagnostic usefulness is shown a dynamic fluctuation between normal control and AD group. To our knowledge, this is the first report of a negative relationship between IL-8 plasma levels and functional status in older individuals affected by AD.

Tumor necrosis factor alpha is a nonspecific, but potent, factor in the development of several psychiatric diseases, including depression and dementia [25]. In the pathogenesis of AD, TNF- $\alpha$ is produced by activated microglia, mainly in response to the $A \beta(1-40)$ and $A \beta(1$ 42) peptides, as well as to oxidative stress [20]. Although the serum concentrations of TNF- $\alpha$ and the soluble TNF- $\alpha$ receptor increase with age [26,27], results regarding the serum TNF- $\alpha$ concentrations in patients with $\mathrm{AD}$ are inconsistent [28-30]. We found decreased TNF- $\alpha$ levels in the plasma from patients with AD compared with the healthy elderly subjects. We observed a similar decrease in this biomarker in the MCI group,
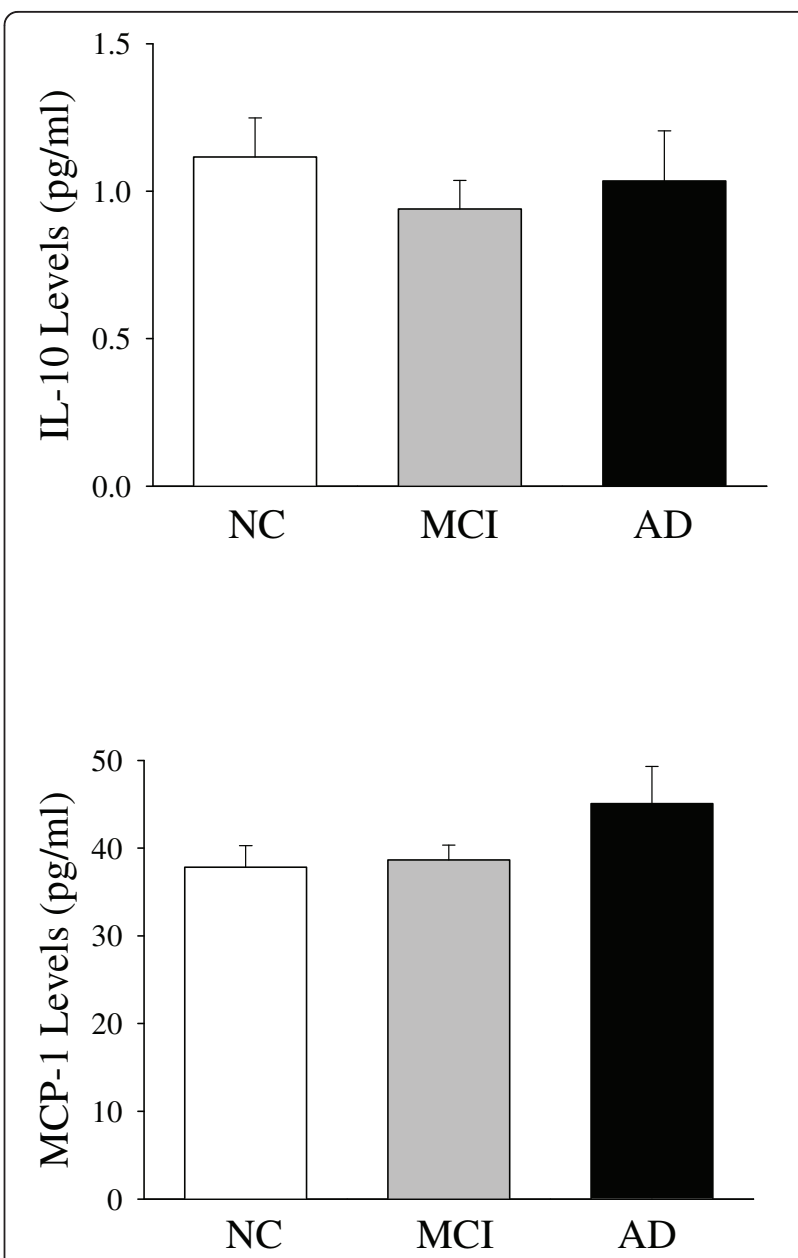

Figure 3 Plasma levels of IL-10 and MCP-1 from control, $\mathrm{MCl}$, and Alzheimer's patients. Results are expressed as the mean $\pm \mathrm{SD}$.

but the decrease was not statistically significant compared to the controls.

Monocyte chemoattractant protein-1 is produced by microglial cells and stimulates astrocytes, which together participate in the degradation of A $\beta$ peptides [20]. Significantly increased MCP-1 levels were found in MCI and mild $A D$, but not in severe AD patients as compared with controls [31], and evidence indicates that the plasma MCP-1 levels could serve as biomarkers to monitor the inflammatory process of AD [32]. We found elevated MCP-1 levels in the plasma from AD patients compared with the healthy elderly subjects, but this increase was not significant.

Interleukin-10 is an anti-inflammatory cytokine in the central nervous system (CNS) that may function to reduce inflammation in $\mathrm{AD}$. However, patients with dementia are reported to have higher mean levels of IL10 [33], and an increase in brain IL-10 has been reported in neurological disease, including $\mathrm{AD}$ [34]. In 


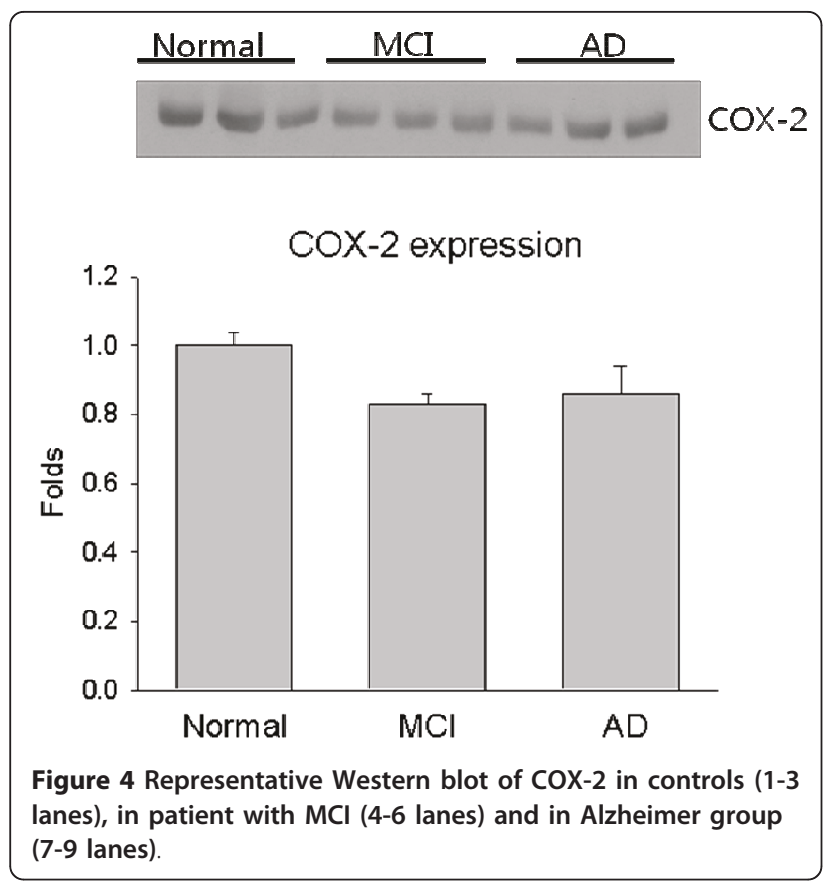

this study, IL-10 was the same in the plasma of AD patients and controls.

The involvement of cytokines in AD is inferred from several changes in their concentrations in both CSF and plasma $[35,36]$. Although whether certain biomarkers from the brain enter the circulation or vice versa is still debated, either microglia or other peripheral cells produce and secrete a wide range of cytokines and chemokines [37]. Circulating cytokines have short half-lives, they may reach high concentrations at the sites of release and much lower concentrations after dilution in blood, and they may circulate bound to molecules that can prevent their detection by immunological methods [38]. All of these may contribute to the great variability in the reported data.

The analysis of these cytokines in these subjects, not available in severe AD cases, would not allow us to determine if these alterations are related to the progression or the severity of the disease. Even though these data are not sufficient to show a trend of cytokine level's alteration according to the progression of disease, it would be served as preliminary data to develop inflammatory biomarker for $\mathrm{AD}$ diagnosis.

\section{Conclusions}

The circulating plasma IL-8 levels were higher in controls than in MCI and AD patients (respectively, $p<$ 0.0001). However, the levels of COX-2 in the three studied groups have been detected, which could not indicate that it is an enzyme which might be induced with cytokine level. Nevertheless, its diagnostic usefulness is shown a dynamic fluctuation between normal control and $\mathrm{AD}$ group.

\section{Acknowledgements}

This study was supported by grants from the Korean National Institute of the Health Intramural Fund (Number 4845-300-210 and 4845-300-260).

\section{Author details}

${ }^{1}$ Center for Biomedical Science, Division of Brain Diseases, National Institute of Health in Korea (KNIH), Osong Health Technology Administration Complex 643 Yeonje-ri, Gangoe-myeon, Chungcheongbuk-do, 363-951, Republic of Korea. ${ }^{2}$ Department of Psychiatry, Korea University Medical College, 516, Gojan-dong, Danwon-gu, Ansan-shi, Gyeonggi-do 425-707, Republic of Korea. ${ }^{3}$ Department of Neurology, Korea University Medical College, 516, Gojan-dong, Danwon-gu, Ansan-shi, Gyeonggi-do 425-707, Republic of Korea.

\section{Authors' contributions}

SM and SW carried out the immunoassay. JH performed the statistical analysis. CS and $\mathrm{MH}$ participated in cohort study. YH and SM participated in its design and coordination.

YY conceived of the study, and participated in its design and coordination. All authors read and approved the final manuscript.

\section{Competing interests}

The authors declare that they have no competing interests.

Received: 10 January 2011 Accepted: 12 May 2011

Published: 12 May 2011

\section{References}

1. Steinman L: Elaborate interactions between the immune and nervous systems. Nat Immunol 2004, 5(6):575-581.

2. Bermejo PE, Martín-Aragón S, Benedí J, Susín C, Felici E, Gil P, Ribera JM, Villar AM: Differences of peripheral inflammatory markers between mild cognitive impairment and Alzheimer's disease. Immunol Lett 2008, 117(2):198-202.

3. Dickson DW, Lee SC, Mattiace LA, Yen SH, Brosnan C: Microglia and cytokines in neurological disease, with special reference to AIDS and Alzheimer's disease. Glia 1993, 7(1):75-83.

4. Griffin WS, Stanley LC, Ling C, White L, MacLeod V, Perrot LJ, White CL, Araoz C: Brain interleukin 1 and S-100 immunoreactivity are elevated in Down syndrome and Alzheimer disease. Proc Natl Acad Sci USA 1989, 86(19):7611-7615.

5. Walker DG, Kim SU, McGeer PL: Complement and cytokine gene expression in cultured microglial derived from postmortem human brains. J Neurosci Res 1995, 40(4):478-493.

6. Yamabe T, Dhir G, Cowan EP, Wolf AL, Bergey GK, Krumholz A, Barry E, Hoffman PM, Dhib-Jalbut S: Cytokine-gene expression in measles-infected adult human glial cells. J Neuroimmuno/ 1994, 49(1-2):171-179.

7. Akiyama H, Barger S, Barnum S, Bradt B, Bauer J, Cole GM, Cooper NR, Eikelenboom P, Emmerling M, Fiebich BL, Finch CE, Frautschy S, Griffin WS, Hampel H, Hull M, Landreth G, Lue L, Mrak R, Mackenzie IR, McGeer PL, O'Banion MK, Pachter J, Pasinetti G, Plata-Salaman C, Rogers J, Rydel R, Shen Y, Streit W, Strohmeyer R, Tooyoma I, Van Muiswinkel FL, Veerhuis R, Walker D, Webster S, Wegrzyniak B, Wenk G, Wyss-Coray T: Inflammation and Alzheimer's disease. Neurobiol Aging 2000, 21(3):383-421.

8. Aisen PS, Schafer KA, Grundman M, Pfeiffer E, Sano M, Davis KL, Farlow MR, Jin S, Thomas RG, Thal LJ: Effects of rofecoxib or naproxen vs. placebo on Alzheimer disease progression: a randomized controlled trial. JAMA 2003, 289:2819-2826.

9. Singh VK, Guthikonda P: Circulating cytokines in Alzheimer's disease. $J$ Psychiatr Res 1997, 31(6):657-660.

10. Richartz E, Stransky E, Batra A, Simon P, Lewczuk P, Buchkremer G, Bartels M, Schott K: Decline of immune responsiveness: a pathogenetic factor in Alzheimer's disease? J Psychiatr Res 2005, 39(5):535-543.

11. van Duijn CM, Hofman A, Nagelkerken L: Serum levels of interleukin-6 are not elevated in patients with Alzheimer's disease. Neurosci Lett 1990, 108(3):350-354. 
12. Shaw LM, Korecka M, Clark CM, Lee VM, Trojanowski JQ: Biomarkers of neurodegeneration for diagnosis and monitoring therapeutics. Nat Rev Drug Discov 2007, 6(4):295-303.

13. Ray S, Britschgi M, Herbert C, Takeda-Uchimura Y, Boxer A, Blennow K, Friedman LF, Galasko DR, Jutel M, Karydas A, Kaye JA, Leszek J, Miller BL, Minthon L, Quinn JF, Rabinovici GD, Robinson WH, Sabbagh MN, So YT, Sparks DL, Tabaton M, Tinklenberg J, Yesavage JA, Tibshirani R, Wyss-Coray T: Classification and prediction of clinical Alzheimer's diagnosis based on plasma signaling proteins. Nat Med 2007, 13(11):1359-1362.

14. Kinoshita J, Clark T: Alzforum. Methods Mol Biol 2007, 401:365-381.

15. Park MH, Jo SA, Jo I, Kim E, Eun SY, Han C, Park MK: No difference in stroke knowledge between Korean adherents to traditional and western medicine - the AGE study: an epidemiological study. BMC Public Health 2006, 6:153.

16. Jo SA, Kim EK, Park MH, Han C, Park HY, Jang Y, Song BJ, Jo I: Glu487Lys polymorphism in the gene for mitochondrial aldehyde dehydrogenase 2 is associated with myocardial infarction in elderly Korean men. Clin Chim Acta 2007, 382(1-2):43-47.

17. Frances A, Mack AH, Ross R, First MB: The DSM-IV Classification and Psychopharmacology. 2000.

18. McKhann G, Drachman D, Folstein M, Katzman R, Price D, Stadlan EM: Clinical diagnosis of Alzheimer's disease: report of the NINCDS-ADRDA Work Group under the auspices of Department of Health and Human Services Task Force on Alzheimer's Disease. Neurology 1984, 34(7):939-944.

19. Petersen RC, Doody R, Kurz A, Mohs RC, Morris JC, Rabins PV, Ritchie K, Rossor M, Thal L, Winblad B: Current concepts in mild cognitive impairment. Arch Neurol 2001, 58(12):1985-1992.

20. Lee KS, Chung JH, Choi TK, Suh SY, Oh BH, Hong CH: Peripheral cytokines and chemokines in Alzheimer's disease. Dement Geriatr Cogn Disord 2009, 28(4):281-287.

21. Xia M, Qin S, McNamara M, Mackay C, Hyman BT: Interleukin-8 receptor B immunoreactivity in brain and neuritic plaques of Alzheimer's disease. Am J Pathol 1997, 150(4):1267-1274.

22. Zhang J, Sokal I, Peskind ER, Quinn JF, Jankovic J, Kenney C, Chung KA, Millard SP, Nutt JG, Montine TJ: CSF multianalyte profile distinguishes Alzheimer and Parkinson diseases. Am J Clin Pathol 2008, 129(4):526-529.

23. Zuliani G, Guerra G, Ranzini M, Rossi L, Munari MR, Zurlo A, Blè A, Volpato S, Atti AR, Fellin R: High interleukin-6 plasma levels are associated with functional impairment in older patients with vascular dementia. $J$ Geriatr Psychiatry 2007, 22(4):305-311.

24. Sekine I, Yamamoto N, Nishio K, Saijo N: Emerging ethnic differences in lung cancer therapy. British Journal of Cancer 2008, 99:1757-1762.

25. Simen BB, Duman CH, Simen AA, Duman RS: TNFalpha signaling in depression and anxiety: behavioral consequences of individual receptor targeting. Biol Psychiatry 2006, 59(9):775-785.

26. Bruunsgaard $H$, Andersen-Ranberg $K$, Jeune $B$, Pedersen AN, Skinhøj $P$, Pedersen BK: A high plasma concentration of TNF-alpha is associated with dementia in centenarians. J Gerontol A Biol Sci Med Sci 1999, 54(7): M357-364.

27. Hasegawa $Y$, Sawada M, Ozaki N, Inagaki T, Suzumura A: Increased soluble tumor necrosis factor receptor levels in the serum of elderly people. Gerontology 2000, 46(4):185-188.

28. Pickering M, Cumiskey D, O'Connor JJ: Actions of TNF-alpha on glutamatergic synaptic transmission in the central nervous system. Exp Physiol 2005, 90(5):663-670.

29. Beattie EC, Stellwagen D, Morishita W, Bresnahan JC, Ha BK, Von Zastrow M: Control of synaptic strength by glial TNFalpha. Science 2002, 295(5563):2282-2285.

30. Stellwagen D, Beattie EC, Seo JY, Malenka RC: Differential regulation of AMPA receptor and GABA receptor trafficking by tumor necrosis factoralpha. J Neurosci 2005, 25(12):3219-3228.

31. Galimberti D, Fenoglio C, Lovati C, Venturelli E, Guidi I, Corrà B, Scalabrini D, Clerici F, Mariani C, Bresolin N, Scarpini E: Serum MCP-1 levels are increased in mild cognitive impairment and mild Alzheimer's disease. 2006, 27(12):1763-1768.

32. Galimberti D, Schoonenboom N, Scarpini E, Scheltens P: Dutch-Italian Alzheimer Research Group. Chemokines in serum and cerebrospinal fluid of Alzheimer's disease patients. Ann Neurol 2003, 53(4):547-548.
33. Angelopoulos P, Agouridaki H, Vaiopoulos H, Siskou E, Doutsou K, Costa V, Baloyiannis SI: Cytokines in Alzheimer's disease and vascular dementia. Int J Neurosci 2008, 118(12):1659-1672.

34. Strle K, Zhou JH, Shen WH, Broussard SR, Johnson RW, Freund GG, Dantzer R, Kelley KW: Interleukin-10 in the brain. Crit Rev Immunol 2001, 21(5):427-449.

35. Teunissen CE, de Vente J, Steinbusch HW, De Bruijn C: Biochemical markers related to Alzheimer's dementia in serum and cerebrospinal fluid. Neurobiol Aging 2002, 23(4):485-508.

36. Blennow K, Hampel H, Weiner M, Zetterberg H: Cerebrospinal fluid and plasma biomarkers in Alzheimer disease. Nat Rev Neurol 2010, 6(3):131-144.

37. Sun $Y X$, Minthon L, Wallmark A, Warkentin S, Blennow K, Janciauskiene S: Inflammatory markers in matched plasma and cerebrospinal fluid from patients with Alzheimer's disease. Dement Geriatr Cogn Disord 2003, 16(3):136-144.

38. De Luigi A, Pizzimenti S, Quadri P, Lucca U, Tettamanti M, Fragiacomo C, De Simoni MG: Peripheral inflammatory response in Alzheimer's disease and multiinfarct dementia. Neurobiol Dis 2002, 11(2):308-314.

\section{Pre-publication history}

The pre-publication history for this paper can be accessed here: http://www.biomedcentral.com/1471-2377/11/51/prepub

\section{doi:10.1186/1471-2377-11-51}

Cite this article as: Kim et al.: Identification of peripheral inflammatory markers between normal control and Alzheimer's disease. BMC Neurology 2011 11:51.

\section{Submit your next manuscript to BioMed Central and take full advantage of:}

- Convenient online submission

- Thorough peer review

- No space constraints or color figure charges

- Immediate publication on acceptance

- Inclusion in PubMed, CAS, Scopus and Google Scholar

- Research which is freely available for redistribution

Submit your manuscript at www.biomedcentral.com/submit
Biomed Central 